Published in final edited form as:

J Matern Fetal Neonatal Med. 2019 October ; 32(19): 3226-3231. doi:10.1080/14767058.2018.1461827.

\title{
Effects of soybean lipid infusion on triglyceride and unbound free fatty acid levels in preterm infants
}

\author{
Thomas Hegyi $^{\mathrm{a}}$, Alan Kleinfeld ${ }^{\mathrm{b}}$, Andrew Huber $^{\mathrm{b}}$, Barry Weinberger ${ }^{\mathrm{c}}$, Naureen Memon ${ }^{\mathrm{d}}$, \\ Weichung Joe Shihe ${ }^{e}$, Mary Carayannopoulos ${ }^{f}$, and William Oh ${ }^{9}$ \\ aDepartment of Pediatrics, Robert Wood Johnson Medical School, Rutgers, State University of \\ New Jersey, New Brunswick, NJ, USA; \\ bFluoresprobe Sciences, San Diego, CA, USA \\ 'Department of Pediatrics, Cohen Children's Medical Center, Northwell Health, New Hyde Park, \\ NY, USA \\ 'MidAtlantic Neonatology Ass. Goryeb Children's Hospital, Morristown, NJ, USA \\ eRutgers School of Public Health, Rutgers University, New Brunswick, NJ, USA \\ fDepartment of Pathology and Laboratory Medicine, Robert Wood Johnson Medical School, \\ Rutgers, the State University of New Jersey, New Brunswick, NJ, USA \\ gDepartment of Pediatrics, Alpert Medical School of Brown University, Providence, RI, USA
}

\section{Abstract}

Objective-To determine the plasma triglyceride (TG) and unbound free fatty acid (FFAu) levels in infants treated with increasing dosages of soybean lipid, intralipid (IL), infusion.

Study design-TG and FFAu levels were measured in 78 preterm infants (BW 500-2000 g; GA 23-34 weeks) using the fluorescent probe ADIFAB2 and enzymatic method.

Results-The infants' BW was $1266.2 \pm 440.7 \mathrm{~g}$ and GA $28.8 \pm 3.1$ weeks. TG levels were 77.4 $\pm 50 \mathrm{mg} / \mathrm{dL}, 140.2 \pm 188 \mathrm{mg} / \mathrm{dL}$ ( $p<.04$ compared to levels during low dose IL infusion) and $135.6 \pm 118 \mathrm{mg} / \mathrm{dL}(p<.004)$, respectively during increased IL rates. FFAu levels were $17.7 \pm 13$ $\mathrm{nM}, 47.3 \pm 102.8 \mathrm{nM}(p=.07)$ and $98 \pm 234 \mathrm{nM}(p=.03)$. TG levels correlated with IL dose, the rate of IL administration, and FFAu levels. TG and FFAu levels were higher in infants below 28 weeks' gestation

Conclusions-Increasing dosage of IL is associated with increasing levels of TG and FFAu, especially in infants below 29 weeks of gestation. The increased level of FFAu suggests inefficient cellular utilization.

\section{Keywords}

Intralipid; triglyceride; unbound free fatty acid; premature infant

Disclosure statement

No potential conflict of interest was reported by the authors. 


\section{Introduction}

Intravenous fat emulsion is an important part of parenteral nutrition in preterm infants [1,2]. The commonly used soybean lipid infusion is intralipid (IL), an emulsion of soy bean oil, egg phospholipids and glycerin, usually administered in a $20 \%$ concentration [3]. The metabolism of IL involves hydrolysis of the triacylglycerols by endothelial lipoprotein lipases in the presence of cofactor apolipoprotein C-II, releasing free fatty acids (FFA) and glycerides [1]. The FFA are used in liver, heart or skeletal muscles as metabolic fuel or enter into adipose tissue to be re-esterified to triglycerides.

The tolerance of lipid infusions is based on the ability to hydrolyze serum triglycerides (TG) into FFA. Elevations of TG are used as markers for lipid intolerance and predictors of the probability of complications involved with the administration of intralipid [4]. Intralipid infusion carries many risks including potential exacerbation of chronic lung disease, displacement of bilirubin from albumin, exacerbation of sepsis, thrombocytopenia and central nervous system injury [1]. Furthermore, significant elevations of plasma FFA levels could result from the lipase-mediated hydrolysis of triglycerides [2]. Lipoprotein lipase activity is increased by advancing gestational and postnatal age, and inhibited by stress and malnutrition, as seen in the small for gestational age infant [5]. FFA levels reflect the ability of the liver to clear and transport them to various organs for their biologic functions. While most of the circulating FFA binds to albumin, a small fraction dissociates from albumin as the free, unbound molecule (FFAu) [6,7]. Elevation of the latter suggests poor transport of FFA to various organ with less nutritional values. To improve our understanding of the metabolic process during IL infusion, we examined TG and FFAu levels in preterm infants treated with increasing dosage of IL. We hypothesized that increased dose of IL will result in increased TG and FFAu levels, the latter a result of inefficient cellular utilization.

\section{Materials and methods}

\section{Patients}

We measured triglyceride (TG) levels in 78 preterm infants weighing under $2000 \mathrm{~g}$ at birth as part of a study to assess the effect of intralipid administration on bilirubin metabolism [8]. Unbound fatty acid (FFAu) levels were also measured using the fluorescent probe ADIFAB2 in the plasma samples. Recruitment was carried out in the Neonatal Intensive Care Unit (NICU) at Rutgers, Robert Wood Johnson Medical School (RWJMS) and the study was approved by the IRBs of Rutgers and the Torrey Pines Institute for Molecular Studies. Parental informed consent was obtained and each infant was treated with IL infusion from 1 to $3 \mathrm{~g} / \mathrm{kg} / \mathrm{d}$ in $1-\mathrm{g} / \mathrm{kg} / \mathrm{d}$ steps increase during the first week of life. Because the laboratory policy is to store all infants blood samples for 7 days it was possible to obtain research samples earlier than the age of the infant at consent.

\section{Study design}

Plasma TG levels were obtained by the clinicians as part of infant parenteral nutrition management with $20 \%$ IL administration. The age of IL initiation was $24.0 \pm 9.2$ hours (range 8-55 hours). The number and timing of TG samples and the decision to withhold, 
reduce or terminate the lipid infusion due to high TG levels were determined by the clinical staff and resulted in a range of the number of triglyceride samples and the age at collection among the infants. TG level data that was accompanied by information on the dose of intralipid and the FFAu levels were utilized for the analysis. The clinical team was unaware of FFAu measurement results.

\section{Blood sampling}

Plasma samples for TG levels were obtained rarely before IL infusion (ILO) and randomly during infusions of 1, 2 and $3 \mathrm{~g} / \mathrm{kg} /$ day (IL1, IL2, IL3). Samples for FFAu levels were obtained from residual samples drawn for clinical indications during those IL dosing windows. These samples were collected immediately after completion of the requested clinical test, processed and frozen. The deidentified samples were stored at $-70{ }^{\circ} \mathrm{C}$ and then shipped to Fluoresprobe Sciences for determination of FFAu. Of note, serum albumin levels were not available for analysis.

\section{TG measurements}

An automated enzymatic method was used for the measurement of plasma TG (Roche Diagnostics, Florham Park, NY), which included primary hydrolysis of the triglycerides and phosphorylation of the resulting glycerol followed by colorimetric detection of the enzymatic products.

\section{FFAu measurements}

FFAu was measured in the plasma sample using a fluorescently labeled mutant of a fatty acid binding protein $[9,10]$. FFAu concentrations were determined using the ADIFAB2 probe [10]. Fluorescence was assessed at two emission wavelengths: 457 and $550 \mathrm{~nm}$ for the FFAu probe (excitation $=375 \mathrm{~nm}$ ). The ratio of fluorescence at the two wavelengths, together with probe characteristics, yielded the FFAu concentrations. Fluorescence was measured at $22{ }^{\circ} \mathrm{C}$ using a handheld ratio fluorometer in which plasma sample volumes were $4 \mathrm{~mL}$ for FFAu measurements and after dilution the total volume was $200 \mu \mathrm{L}$ so that FFAu was measured at 50 fold dilution of the plasma sample $[9,10]$.

\section{Statistical analysis}

The outcome variables (shown as mean \pm standard deviation) were treated as continuous, normally distributed and examined with the Student $t$ test and chi-square test to document TG level differences at different dosages of IL. IL infusion rate was calculated using the IL dose and infant weight at time of IL administration. The changes in TG levels as a function of increasing dose of IL were analyzed by repeated measures analysis. Correlation analysis was performed to evaluate the relationship between TG levels and IL administration rate and FFAu concentrations. The analyses were performed with Statistica (StatSoft, Palo Alto, CA); $p<.05$ was considered significant. 


\section{Results}

One hundred thirty-three paired TG and FFAu levels were obtained during the first 10 days of life in 78 preterm infants with a birth weight of $1266.2 \pm 440.7 \mathrm{~g}$ and gestational age 28.8 \pm 3.1 weeks.

Because the number of samples is small for pre-IL infusion, we compared the changes in TG and FFAu when the IL dose was increased from $1 \mathrm{~g} / \mathrm{kg} / 24$ hours to 2 and $3 \mathrm{~g} / \mathrm{kg} / 24$ hours. As shown in Table 1, TG increased significantly when the IL dose was increased from 1 to 2 and $3 \mathrm{~g} / \mathrm{kg} / 24$ hours ( $p$ values, .04 and .004), respectively. The FFAu also increased when IL dose was increased from 1 to 2 and $3 \mathrm{~g} / \mathrm{kg} / 24$ hours, ( $p$ values, .07 and .03, respectively).

TG levels significantly correlated with IL dose $(\mathrm{r}=.19)$, with the rate of IL administration ( $\mathrm{r}$ $=.24)$, as shown in Figure 1, and with FFAu levels $(\mathrm{r}=.29)$, as shown in Figure 2. Interestingly, FFAu levels did not correlate with the rate of IL infusion.

Table 2 shows that TG levels were higher in infants below 29 weeks' gestation, with significant differences noted at $1 \mathrm{~g} / \mathrm{kg} / 24$ hours $(p=.018)$ and $2 \mathrm{~g} / \mathrm{kg} / 24$ hours $(p=.009)$ infusions. FFAu levels were higher in these infants $(p=.07)$ during infusions of 2 and 3 $\mathrm{g} / \mathrm{kg} / 24$ hours. Among the 25 infants below 29 weeks of gestation (GA-gestational age (BW) $808.2 \pm 224.9 \mathrm{~g}$, GA $25.4 \pm 1.7$ weeks), $7(28.0 \%)$ had at least one TG level $>250 \mathrm{mg} / \mathrm{dL}$, compared to $3(5.7 \%)$ of the $53 \leq 29$ weeks (BW $1532.6 \pm 289.2$ g, GA $30.8 \pm 1.7$ weeks) ( $p$ $=.01)$.

\section{Discussion}

Preterm infants often cannot be fed adequately via the enteral route and require parenteral nutrition to provide the various nutrients and energy. Intravenous lipid emulsions, important constituents of parenteral nutrition, provide increased caloric intake and long-chain polyunsaturated fatty acids necessary for normal neural development and function. These lipids are metabolized by lipoprotein lipases releasing triglycerides and free fatty acids which can be used as metabolic fuel in the liver, heart and skeletal muscles or which can enter fat cells to be either re-esterified to triglycerides or stored [11]. Most of the FFA in serum is bound to albumin but a small portion is unbound [12]. The unbound free fatty acid (FFAu) level in adults is $1.5 \pm 0.9 \mathrm{nM}$ [13] and in term infants $13.9 \pm 3 \mathrm{nM}$ [14].

The inability to effectively clear triglycerides leads to hypertriglyceridemia, which has been associated with a number of adverse effects [15], including complication of disorders of preterm infants. While the inadvertent overdose of lipid emulsions has resulted in severe hypertriglyceridemia causing severe clinical symptoms, the level of safety has been suggested to be below $250 \mathrm{mg} / \mathrm{dL}$ [16], although different TG concentration norms have also been recommended [1]. These ranges are 100-150, <200, and <250 mg/dL [1]. Several reviews have examined the metabolism of triglycerides in intravenous fat infusions [2,17]. Morris noted peak TG level was $116.8 \pm 60.9 \mathrm{mg} / \mathrm{dL}$, which declined rapidly after the cessation of IL. TG levels reflect a combination of endogenous and infused TG, controlled by the variability of IL metabolism by individual infants. Thus, that measurement of lipid fractions is only useful if the endogenous and infused TG can be separated, measures usually 
not available to the clinician who has to rely on total TG levels to assess the risk of the lipid infusion [18].

The study suffers from the random collection of samples due to the discretion of the clinicians, but, in spite of this limitation, we are confident in the results which show that increasing dosage of IL is associated with increasing TG and FFAu levels. We have demonstrated the relationship between IL dose and FFAu concentrations in previous publications [19]. When lipid emulsion is infused, the TG is hydrolyzed by lipoprotein lipase via C-II in the endothelial surface to FFA which in turns is taken up by various organs for metabolic fuel and to fat tissue to be re-esterified back to TG [20]. If the preterm infants had low lipoprotein lipase (LPL) activity, the result will be a high TG but low FFAu levels. We speculate that in our study subjects IL dose increase was accompanied by reduced metabolic utilization of FFAu resulting in increased FFAu level. The latter could cause a dissociation of C-II from LPL inhibiting the hydrolysis accounting for the elevation of TG. It appears that the increased dose of IL may not achieve the desired increase in metabolic fuel as expected.

It is of interest that the rate of IL infusion correlated with TG levels with a number of infants manifesting TG above $250 \mathrm{mg} / \mathrm{dL}$ in spite of limiting the infusion rate below $0.15 \mathrm{~g} / \mathrm{kg} / \mathrm{hour}$, which was suggested to be a safe rate [1]. FFAu levels also increased, correlating with TG levels, but there was no relationship with FFAu levels and TG when the latter exceeded 250 $\mathrm{mg} / \mathrm{dL}$.

Our findings are consistent with the previous report of the sensitivity of infants below 29 weeks of gestation to manifesting elevated levels of TG due to IL infusion [21]. The elevated FFAu and TG levels suggest a deficiency in the metabolism of IL and question the benefits of intravenous fat infusion if the nutritional advantages are absent compared to the potential risks.

Our results also demonstrated that FFAu levels in the preterm infants are not predictable and often elevated. The potential toxicity of excessive FFAu levels in this population remains to be elucidated. In adults, elevated levels of FFAu inhibit T lymphocyte signaling [22]. In a previous investigation, we observed that in unstressed newborn rats, FFAu levels decreased over the course of the first week of life, while levels in rats exposed to severe hypoxic conditions were significantly elevated [23]. The elevated FFAu levels were thought to be due to inflammatory mediator caused lipolysis. In another study, we showed that umbilical cord FFAu levels were significantly higher in infants with lower Apgar scores with an inverse correlation noted between umbilical cord FFAu levels and cord $\mathrm{pH}$ [24]. These findings were thought to be due to increased serum catecholamine levels during the stressful period or, alternately, reduced myocardial uptake of FFA during ischemia $[25,26]$.

The unbound free fatty acid (FFAu) level in adults is $1.5 \pm 0.9 \mathrm{nM}$ and in term infants 13.9 $\pm 3 \mathrm{nM}$. The high FFAu levels in preterm infants are like and even exceed those in adults with a greatly increased risk of death highly correlated with elevated FFAu levels. In the TIMI II trial of ST-elevation myocardial infarction, the median FFAu levels in the fourth quartile of 1864 patients was $10 \mathrm{nM}$ and these patients had a seven-fold greater risk of death 
relative to those in the first quartile (median $1.9 \mathrm{nM}$ ) [13]. Elevated levels of FFAu may not only be associated with neonatal mortality [27] but with increased morbidity since albuminbound bilirubin is displaced by FFAu thus increasing the risk bilirubin related neurotoxicity [28].

In conclusion, intralipid administration in large doses raises TG and FFAu levels in premature infants and increases the risk of potential morbidity and mortality due to bilirubin displacement. TG and FFAu levels are unpredictable and thus require monitoring during intralipid administration. However, the utility of intralipid administration to provide calories needs to be addressed in infants who demonstrate intolerance to the infusion.

\title{
Acknowledgments
}

\author{
Funding \\ All phases of the study were supported by NICHD, grant number 1RO3 HD077422-01A1 and R44HD080412-02. \\ Kleinfeld is the founder of and partner in Fluoresprobe Sciences. Huber is Director of Research at Fluoresprobe \\ Sciences and his salary is paid by Fluoresprobe Sciences.
}

\section{References}

[1]. Salama GS, Kaabneh MA, Almasaeed MN, et al. Intravenous lipids for preterm infants: a review. Clin Med Insights Pediatr 2015;9:25-36. [PubMed: 25698888]

[2]. Stahl GE, Spear ML, Hamosh M. Intravenous administration of lipid emulsions to premature infants. Clin Perinatol 1986;13:133-162. [PubMed: 3514048]

[3]. Bryan H, Shennan A, Griffin E, et al. Intralipid-its rational use in parenteral nutrition of the newborn. Pediatrics 1976;58:787-790. [PubMed: 825820]

[4]. Amini E, Didban A, Eabrhim B, et al. Changes of total plasma triglycerides in neonates treated with intralipid: a Pilot Study. Iran J Pediatr 2015;25:e256. [PubMed: 26199703]

[5]. Andrew G, Chan G, Schiff D. Lipid metabolism in the neonate. I. The effects of intralipid infusion on plasma triglyceride and free fatty acid concentrations in the neonate. J Pediatr 1976;88:273278. [PubMed: 814225]

[6]. Spector AA. Fatty acid binding to plasma albumin. J Lipid Res 1975;16:165-179. [PubMed: 236351]

[7]. Richieri GV, Anel A, Kleinfeld AM. Interactions of long-chain fatty acids and albumin: determination of free fatty acid levels using the fluorescent probe ADIFAB. Biochemistry 1993;32:7574-7580. [PubMed: 8338853]

[8]. Hegyit T, Kleinfeld A, Huber A, et al. Effects of soy-bean lipid infusion on unbound fatty acids and unbound bilirubin in preterm infants. J Pediatr 2017; 184:45-50. [PubMed: 28108102]

[9]. Huber AH, Zhu B, Kwan T, et al. Fluorescence sensor for the quantification of unbound bilirubin concentrations. Clin Chem 2012;58:869-876. [PubMed: 22395024]

[10]. Huber AH, Kampf JP, Kwan T, et al. Fatty acid-specific fluorescent probes and their use in resolving mixtures of unbound free fatty acids in equilibrium with albumin. Biochemistry 2006;45:14263-14274. [PubMed: 17128966]

[11]. Putet G Lipid metabolism of the micropremie. Clin Perinatol 2000;27:57-69. [PubMed: 10690564]

[12]. Spector AA, Fletcher JE. Transport of fatty acid in the circulation. In: Dietschy JM, Gotto AM, Ontko E, editors. Disturbances in lipid and lipoprotein metabolism Bethesda, MD: American Physiologic Society; 1978 p. 229-249.

[13]. Huber AH, Kampf JP, Kwan T, et al. Usefulness of serum unbound free fatty acid levels to predict death early in patients with ST-segment elevation myocardial infarction (from the 
Thrombolysis In myocardial infarction [TIMI] II trial). Am J Cardiol 2014;113: 279-284. [PubMed: 24176067]

[14]. Patel MN, Kleinfeld AM, Richeiri GV, et al. Serum levels of unbound free fatty acids. I: Normative data in term newborn infants. J Am Coll Nutr 1997;16:81-84. [PubMed: 9013438]

[15]. Periera GR, Fox WW, Stanley CA, et al. Decreased oxygenation and hyperlipemia during intravenous fat infusions in premature infants. Pediatrics 1980;66:26-30. [PubMed: 7402788]

[16]. Adamkin DH, Gelke KN, Andrews BF. Fat Emulsions and hypertriglyceridemia. J Parenter Enter Nutr 1984;8:563-567.

[17]. Carpentier YA. Intravascular metabolism of fat emulsions: the Arvid Wretlind Lecture, ESPEN 1988. Clin Nutr 1989;8:115-125. [PubMed: 16837276]

[18]. Morris S, Simmer K, Gibson R. Characterization of fatty acid clearance in premature neonates during intralipid infusion. Pediatr Res 1998;43:245-249. [PubMed: 9475292]

[19]. Ruben S, Kleinfeld AM, Richeiri GV, et al. Serum levels of unbound free fatty acids. II: The effect of intralipid administration in premature infants. J Am Coll Nutr 1997;16:85-87. [PubMed: 9013439]

[20]. Peterson J, Bihain BE, Bengtsson-Olivecrona G, et al. Fatty acid control of lipoprotein lipase: a link between energy metabolism and lipid transport. Proc Natl Acad Sci USA 1990;87:909-913. [PubMed: 2300584]

[21]. Gustafson A, Kjellmer I, Olegård R, et al. Nutrition in low-birth-weight infants. I. Intravenous injection of fat emulsion. Acta paediatr Scand 1972;61:149-158. [PubMed: 5062274]

[22]. Stulnig TM, Berger M, Roden M, et al. Elevated serum free fatty acid concentrations inhibit T lymphocyte signaling. FASEB J 2000;14:939-947. [PubMed: 10783148]

[23]. Weinberger B, Carbone T, England S, et al. Effects of perinatal hypoxia on serum unbound free fatty acids and lung inflammatory mediators. Biol Neonate 2001;79:61-66. [PubMed: 11150832]

[24]. Yuvienco JM, Dizon ME, Kleinfeld A, et al. Umbilical cord unbound free fatty acid concentration and low Apgar score. Am J Perinatol 2005;22:429-436. [PubMed: 16283602]

[25]. Richieri GV, Ogata RT, Kleinfeld AM. A fluorescently labeled intestinal fatty acid binding protein. Interactions with fatty acids and its use in monitoring free fatty acids. J Biol Chem 1992;267:23495-23501. [PubMed: 1429693]

[26]. Kamihara S, Yokota M, Iwase M, et al. Early detection of myocardial ischemia by myocardial free fatty acid extraction in patients with exercise-induced angina pectoris. Am J Cardiol 1989;64:180-185. [PubMed: 2741828]

[27]. Hegyi T, Kathiravan S, Stahl GE, et al. Unbound free fatty acids from preterm infants treated with intralipid decouples unbound from total bilirubin potentially making phototherapy ineffective. Neonatology 2013;104:184-187. [PubMed: 23970042]

[28]. Amin SB. Effect of free fatty acids on bilirubin-albumin binding affinity and unbound bilirubin in premature infants. J Parenter Enter Nutr 2010;34:414-420. 


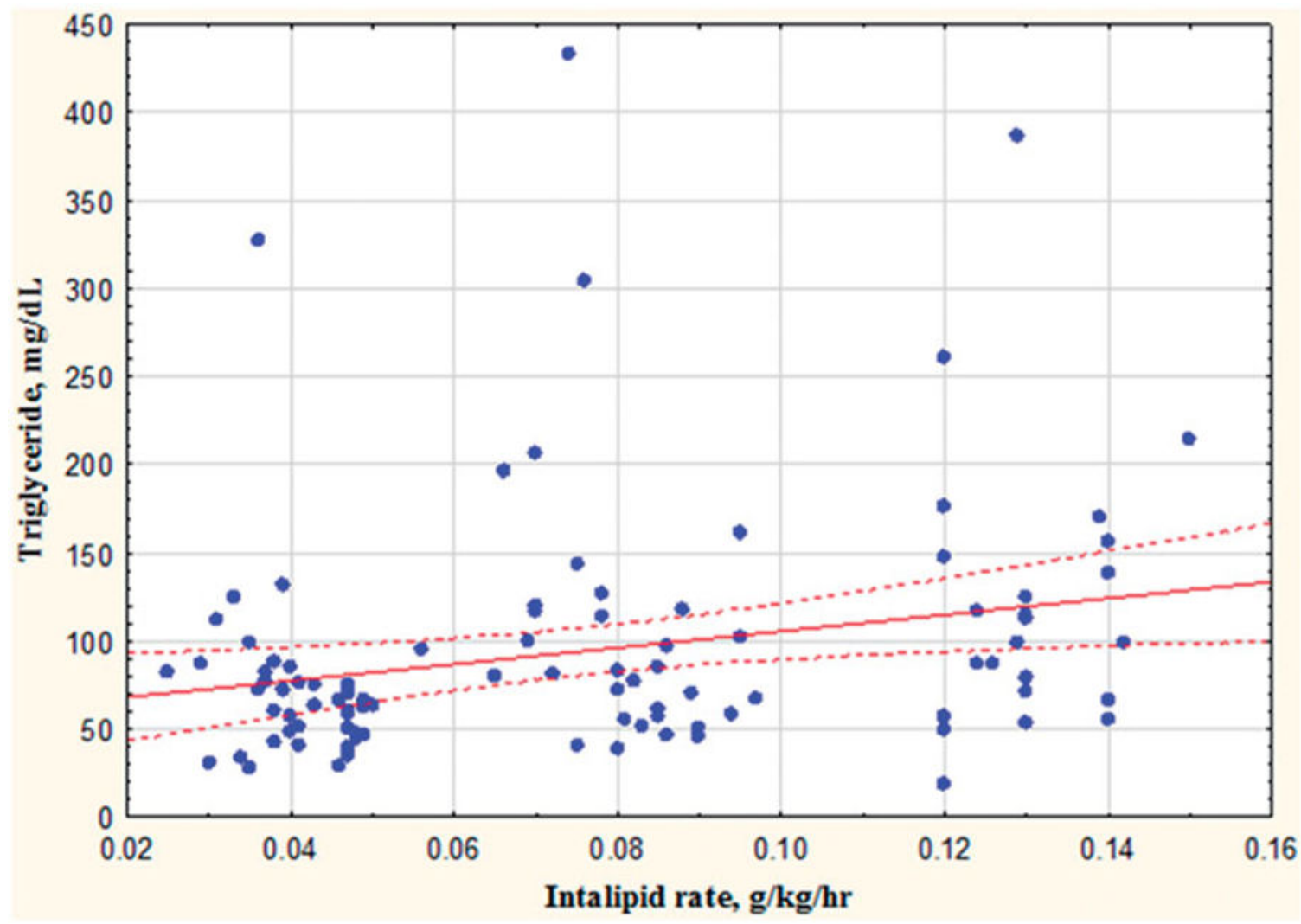

Figure 1.

The rate of intralipid administration and triglyceride levels. Figure 1 demonstrates rate of Intralipid administration from 0.02 to $0.15 \mathrm{~g} / \mathrm{kg} /$ hour and serum triglyceride levels from 20 to $450 \mathrm{mg} / \mathrm{dL}$. $(\mathrm{r}=.24, p<.05)$. 


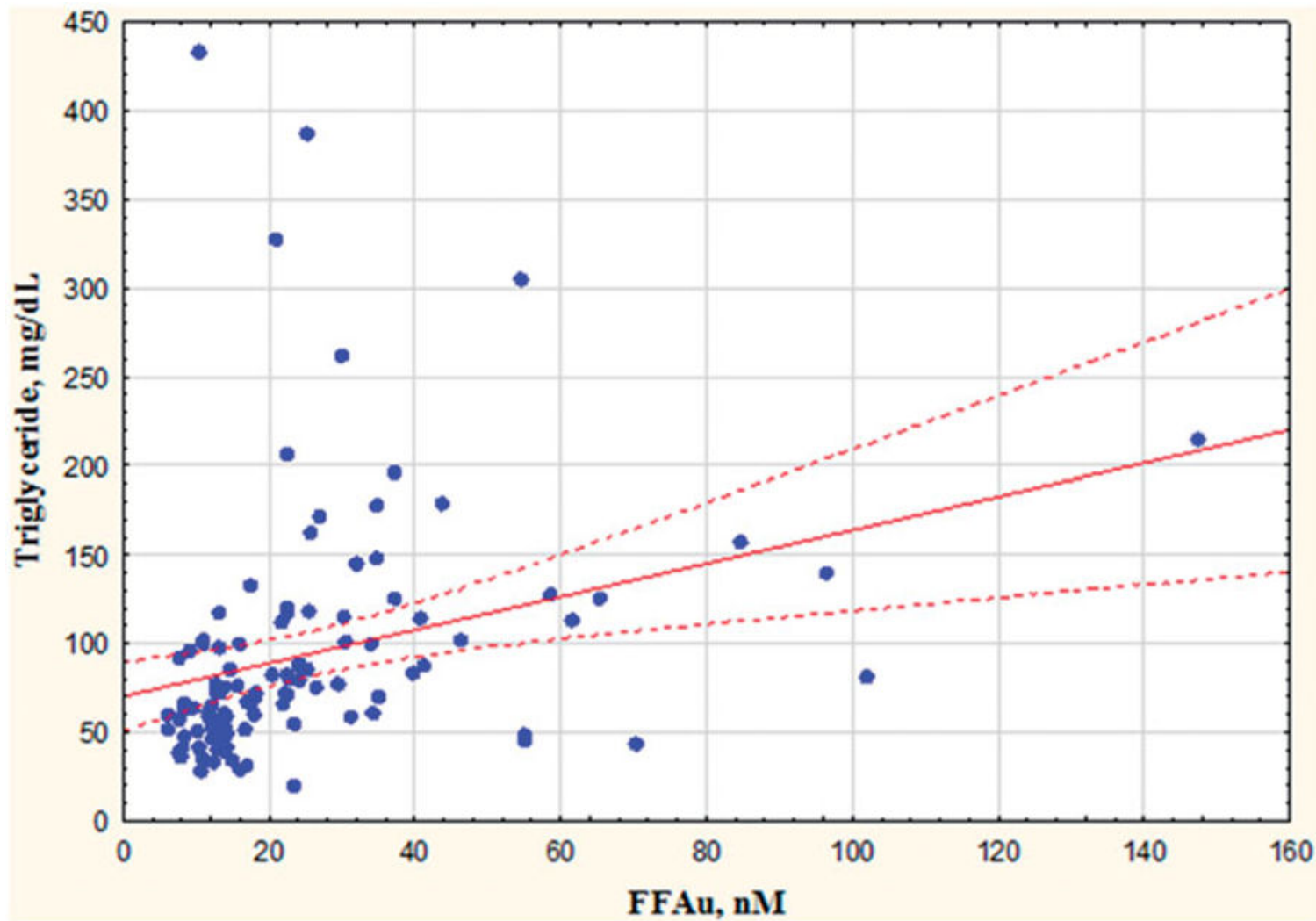

Figure 2.

Unbound free fatty acid levels (below $200 \mathrm{nM}$ ) and triglyceride levels. Figure 2 shows the relationship between FFAu and triglyceride (TG) levels $(\mathrm{r}=.29, p<.05)$. 


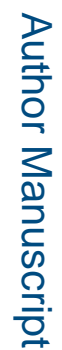

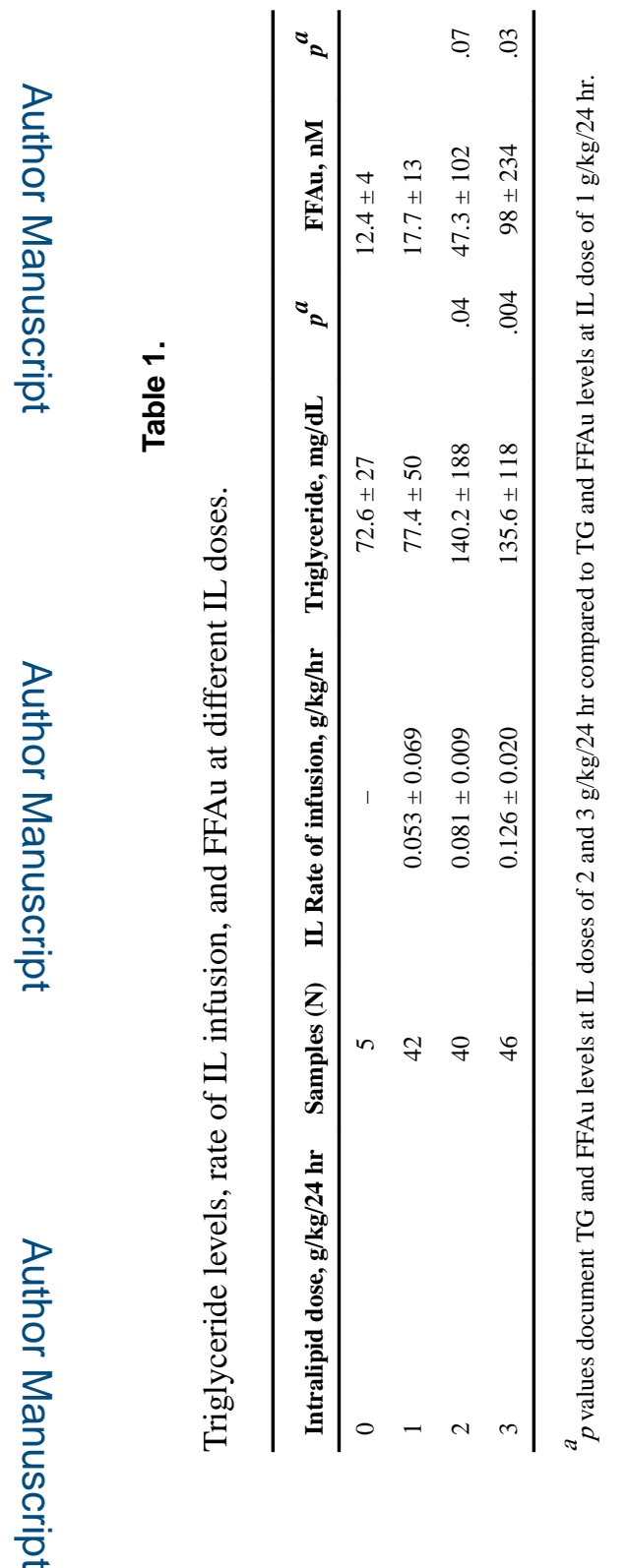

J Matern Fetal Neonatal Med. Author manuscript; available in PMC 2019 October 01. 
Table 2.

TG and FFAu Levels with reference to gestational age.

\begin{tabular}{|c|c|c|c|c|c|c|}
\hline \multirow[t]{2}{*}{ IL dose $\mathrm{g} / \mathrm{kg} / 24 \mathrm{~h}$} & \multicolumn{3}{|c|}{ Triglyceride, $\mathbf{m g} / \mathbf{d L}$} & \multicolumn{3}{|c|}{ FFAu, nM } \\
\hline & $<29$ wks & $\geq 29$ wks & $\mathbf{p}$ & $<29$ wks & $\geq 29$ wks & $p$ \\
\hline 0 & $57 \pm 21 n=3$ & $97 \pm 8 n=2$ & .09 & $14.4 \pm 3 n=3$ & $9.5 \pm 3 n=2$ & .18 \\
\hline 1 & $97.1 \pm 64 n=19$ & $61.1 \pm 26 n=23$ & .018 & $18.7 \pm 14 n=19$ & $16.8 \pm 11 n=23$ & .63 \\
\hline 2 & $227.9 \pm 265 n=17$ & $75.3 \pm 30 n=23$ & .009 & $80.2 \pm 152 n=17$ & $21.8 \pm 11 n=23$ & .07 \\
\hline 3 & $160.6 \pm 128 n=19$ & $118 \pm 128 n=27$ & .23 & $172 \pm 332 n=19$ & $45.7 \pm 109 n=27$ & .07 \\
\hline
\end{tabular}

